\title{
Generating political support for cardiac surgical care in resource-limited contexts: experience from Nepal
}

\author{
Bhagawan Koirala \\ Department of Cardiothoracic and Vascular Surgery, Manmohan Cardiothoracic Vascular and Transplant Center, Tribhuvan University, Kathmandu, \\ Nepal \\ Correspondence to: Bhagawan Koirala. Department of Cardiothoracic and Vascular Surgery, Manmohan Cardiothoracic Vascular and Transplant \\ Center, Tribhuvan University, Kathmandu, Nepal. Email: koiralabhagawan@gmail.com.
}

\begin{abstract}
Generating political support for a cardiac surgical program in limited resource requires extensive engagement with stakeholders including the public and the policy-makers. There are competing priorities at the national level in health, including but not limited to, maternal and child health, prevention and treatment of infectious diseases, and management of other non-communicable and surgical conditions. The relatively high initial establishment cost of a cardiac surgical program and need for a highly skilled surgical team are also the barriers for establishment of a national program. It is thus important to demonstrate that the cardiac surgical programs can be sustainable and have huge impact in saving lives, mostly at younger age, thereby having greater impact in reducing Disability Adjusted Life Years (DALY). Keeping accurate data and producing the evidence for cost effectiveness of the program in the long run is probably the most important factor for public and political support. Highly cost-effective surgical treatments for cardiac conditions are: congenital septal defects, selected cyanotic heart diseases and repair of a rheumatic mitral valve disease. While surgical treatment of most of these conditions are curable, repair of a rheumatic heart valve gives a lasting solution to most young people with rheumatic heart disease (RHD). Medical, psychosocial and rehabilitative services to treat a wide range of cardiac conditions and other non-communicable diseases (NCDs) are also highly cost-effective and fiscally achievable. As much as it is important to ensure technical efficiency and high quality of care, it is also critical to communicate this to the general public and policy makers. Demonstrations of small models of success are the best way to assure them that although ambitious, establishment of cardiac surgical care is feasible, achievable and impactful investment in the national health system.
\end{abstract}

Keywords: Cardiac surgery; resource limited settings; experience from Nepal

Received: 09 June 2021; Accepted: 05 March 2022; Published: 30 September 2022.

doi: 10.21037/asj-21-48

View this article at: https://dx.doi.org/10.21037/asj-21-48

\section{Introduction}

Non-communicable diseases (NCDs) are the leading causes of deaths in the world. The four main NCDscardiovascular diseases, cancers, chronic lung diseases and diabetes kill three in five people worldwide (1). For the poorest of our world, NCDs and injuries (NCDIs) account for more than a third of their burden of disease. This burden includes almost 800,000 deaths annually among those aged younger than 40 years, more than human immunodeficiency virus (HIV), tuberculosis and maternal deaths combined. Despite already living in abject poverty, between 19 and 50 million of the poorest billion spend a catastrophic amount of money each year in direct out-ofpocket costs on health care as a result of NCDIs (2).

In most low-income countries, however, NCDs are conventionally thought to be disease of lifestyle and rich people. Since there is a high prevalence of many infectious diseases, the attention is often drawn to those acute conditions. Setting up treatment facilities for NCDs, particularly for cardiac conditions is considered expensive and financially unsustainable. Politicians and policy 
makers often dismiss the importance of early detection and treatment of these NCDs. Most countries, even if they recognize the public health importance of NCDs, do so only for four common NCDs, namely, cardiovascular disease, cancer, chronic lung diseases and diabetes. Even the World Health Organization (WHO) global monitoring framework to enable global tracking of progress in preventing and controlling major NCDs includes these four diseases conditions (1).

Nepal is a low-income country in South Asia, with a population of approximately 30 million. coronary artery disease and cancer is on the rise. However, advanced rheumatic and congenital heart disease (CHD) are still among the most common cardiac causes of hospital admission in Nepal (3). Rheumatic heart disease (RHD) is the most common acquired heart disease in children in developing countries (4). Several studies published on RHD in Nepal (5-8) showed the prevalence of RHD among school children to be between $0.9-1.35$ per thousand. But the subclinical prevalence of RHD among the school children seems to be very high if an echocardiography is used to screen them. Shrestha et al. showed that the RHD affects 1 in 100 schoolchildren in eastern Nepal, is primarily clinically silent, and may be more common among girls (9).

Similarly, CHDs, which affect roughly $1 \%$ of all live births around the world, have high impoverishment impact on Nepalese population as that on poor communities. A survey on Nepal's living standards done in 2010 showed that three conditions, namely injuries, gastro-related diseases and heart diseases had the highest impoverishment impact on families (10). Even today, Nepal has very high out of pocket expenditure on health care delivery. And thus, in the absence of a national insurance or specific support program, the treatment of CHDs and RHDs are expensive and would generally be out of reach for most Nepalese families. This article aims to demonstrate that having a national cardiac surgical program is possible and cost effective in along run even in resource limited settings.

\section{Generating political support}

Just about 25 years ago, Nepal had no dedicated cardiac surgical or interventional program. There were few cardiologists, who could offer medical therapy for limited cardiac conditions. Only option for people would have been either to go out of country for treatment or live with medical therapy, even if that was a surgical condition. Only those who were well off chose to go for treatment abroad and many would just sell their properties to avail the treatment. The author was one of the pioneers of cardiac surgical program in the early days (11) and has an insightful experience on the challenges faced in the pursuit.

The first few cases that were performed at the Tribhuvan University Teaching Hospital were backed by Leonard Bailey and his team from Loma Linda University, California, USA. Sustaining the program was an uphill task with almost non-existent funding, competing specialties and lack of leadership commitment.

In the mid-nineties, the government finally decided to set up a dedicated heart hospital at a run-down old shoe factory premises. Several years later, a law was enacted to make the hospital autonomous from the ministry of health, and hospital was named "Shahid Gangalal National Heart Center (SGNHC)". The author was appointed as the executive director of the hospital in 2001 and had the responsibility to transform the old "shoe factory" into a functioning heart hospital.

\section{Case presentation}

Sometime in 2002, in the anniversary event of the heart hospital, we had organized a small ceremony with some invited guests from medical community, civil service and our own staff. The health minister was the chief guest as the chair of the board of directors of the hospital. The author (then the director of the hospital) presented the progress report of the hospital. There were few remarks from the fraternity, that was mostly praise to the progress made within such a short time. In the final remarks, given by the minister, he severely criticized the whole concept of having a heart hospital in a country where there were not even enough doctors to see common diseases, and nobody to do post-mortem studies in the districts. He condemned those who took the initiative to open the hospital and suggested that it should be closed. Everyone felt insulted and the guests felt awkward.

During the tenure of the author as the executive director of the heart hospital between 2001 and 2009, he had to work with 14 ministers as the chair of the board of directors. That is how unstable the government was. Most ministers disdained the idea of a dedicated hospital for a seemingly low-priority disease. After numerous briefings and site visits only, they would start appreciating and many of them became our allies by the time they finished their short tenure as minister. This was further reinforced by the rapidly growing positive public support. 
Currently, SGNHC, a government owned tertiary cardiac center in Kathmandu is busy high volume cardiac center with almost all the treatment modalities for most cardiac conditions. RHD is among the top three reasons for admission in cardiology department and also the second most common cause of cardiac surgery at that center. Approximately 500 open heart surgeries, which constitutes about one third of all the surgeries, done at the National Heart Center are for RHDs. And almost the same number of percutaneous transcatheter mitral commissurotomies (PTMCs) are being performed there (12). Another publicly funded institute, Manmohan Cardiothoracic and Vascular Center of the Tribhuvan University also performs a sizable number of cardiac surgeries and interventions. In the ensuing days, several national-level policies were passed to make the cardiac care more accessible to all. This is briefly highlighted in the Lancet NCDI Poverty Commission report, in which it the cardiac surgical programs in Nepal has been described as "high volume, low cost and high quality publicly funded cardiac surgery in a low-income country (Nepal)" (2).

Beginning in 1995, Nepal-with a per-capita gross domestic product at the time of US\$206-began to publicly finance open heart surgery; first through the SGNHC, and later through Manmohan Cardiothoracic and Transplant Center (since 2011). Nepal increased its volume of valvular and congenital heart surgery up to more than 2,000 cases per year by 2015 . The 30 -day surgical mortality for single valve replacements has been below $5 \%$, and in the order of 1-2\% for correction of septal defects (both good by international standards). Both institutions have maintained low operating expenses, and the average cost for a double valve replacement is around US $\$ 2,500$, whereas the cost of simple congenital heart surgery is around US\$2,000. Although these costs are low, they are still unaffordable to Nepal's the poorest. To increase access to cardiac surgery, the Government of Nepal established the Child Assistance Program to fully subsidize cardiac care for those aged under 15 years. Additionally, the Senior Citizen Program finances care of patients aged over 75 years. Patients between the ages of 15 and 75 years who are poor are eligible to apply for government support up to US\$1,000 through the Poor Patients Relief Fund. In 2016, the Government of Nepal announced a new initiative to fully subsidize all care, including surgery, for patients with RHD. Public financing for cardiac surgery for the poor with severe cardiac diseases in Nepal has developed local capacity and supported high surgical volumes with high quality at low cost. Nepal is creating a successful and sustainable model for equitable cardiac care in resource-poor settings (3).

The currently established public cardiac centers are located in Kathmandu. Many patients still face logistical challenges to arrive to Kathmandu for surgeries. Expanding the cardiac surgical services outside of Kathmandu will have to be justified by cost benefit ratio. This will happen when the need is justified and well communicated to the policy makers and financing schemes are well designed. Currently many provincial and district hospitals and some mobile international normalized ratio (INR) clinics do the follow ups of the postoperative patients including the management of anticoagulation when appropriate.

\section{What drove this change?}

\section{Data and the narratives}

It is critically important to have accurate data to highlight upon the magnitude of the problem and providing insights through equity lens for advocacy purposes. National data on NCDs and poverty, the burden of heart disease, unit cost of services, Disability Adjusted Life Years (DALY) and years of life lost (YLL) averted, return on the investment, and potential positive impact on the health and economy of the country are all important to know and share. Addressing NCDI Poverty is one of the greatest benefits that could be realized by universal health coverage (UHC). Highly costeffective surgical treatments for cardiac conditions are: congenital septal defects, selected cyanotic heart diseases and repair of a rheumatic mitral valve disease. While surgical treatment of most of these conditions are curable, repair of a rheumatic heart valve gives a lasting solution to most young people with RHD. Medical, psychosocial and rehabilitative services to treat a wide range of cardiac conditions and other NCDs are also highly cost-effective and fiscally achievable. These facts need to be demonstrated by the team that is leading these programs for politicians to support them.

However, what is of even more value in garnering government support is the voices of patient and civil society. Most politicians, have as the top priority, direct, visible benefit to their constituents. So, the public opinion matters and the public opinion are built on the patient narratives. The opinions are formed based on volume, the outcome and the relationships with the patients. The most powerful tool for advocacy was to give the politicians a popular yet a meaningful slogan. We rallied the slogan of 'No child in this country shall die of heart disease because of poverty'. 
Although ambitious, it was achievable. With perseverance, and an unwavering dedication of the team, we have been able to secure public financing for all the inpatient cardiac care including cardiac surgeries for children under the age of 15 years, for all patients with RHDs, and for senior citizens over the age of 75 years.

\section{Volume and quality of service}

Volume and quality are interrelated. Initial quality work with good outcomes is vital for the program. But at the same time, one needs to maintain certain minimum volume to be able to keep the quality, keep training younger generation, increase efficiency and improve cost saving.

Volume and quality of the service also provide the team and the team leader a voice, that eventually can gather support for the program that so often gets neglected.

\section{Role of media}

There is a major role of media in shaping public and the government perspectives. By and large, they reflect the public opinion and influence heavily on how the politicians draw conclusions and make decisions. Keeping people informed of the new developments and to some extent, the future plans are of paramount importance. People need visible outputs rather than lofty ideals. It is even better, when one can beat the expectations of the public. In an environment of cynicism and hopelessness, shining out as an outlier will gain an unusual traction in public support.

\section{The next steps}

Now that the programs are well established and financially stable, it will be relatively easy to sustain them. But we need to continue to work with the policy makers to get the right financial schemes for all cardiac conditions and minimize the out-of-pocket expenditure for all age groups. Similarly, maintaining quality of service by collaborating with international academic institutions and by keeping quality improvement system in place will be of paramount importance. Maintaining high standards of care shall be crucial to continue to get support from public and the politicians.

\section{Conclusions}

The history of cardiac care services development and expansion in Nepal to reach even to the most impoverished population stands out as a beacon of hope to other lowresource settings as well. It is a testimony to the fact that even in most adverse circumstances, clarity in vision, commitment to service, and a perseverant approach will yield unprecedented results. While, the importance of data and evidence cannot be undermined, it is equally important to be able to build simple but compelling narratives around the cause through visible achievements that exceed public expectations, and creating platforms for the voices of public through media.

\section{Acknowledgments}

Funding: None.

\section{Footnote}

Provenance and Peer Review: This article was commissioned by the Guest Editors (Dominique Vervoort and Marcelo Cardarelli) for the series "Addressing Global Disparities in Pediatric and Congenital Cardiac Care" published in AME Surgical fournal. The article has undergone external peer review.

Peer Review File: Available at https://asj.amegroups.com/ article/view/10.21037/asj-21-48/prf

Conflicts of Interest: The author has completed the ICMJE uniform disclosure form (available at https://asj.amegroups. com/article/view/10.21037/asj-21-48/coif). The series "Addressing Global Disparities in Pediatric and Congenital Cardiac Care" was commissioned by the editorial office without any funding or sponsorship. The author has no other conflicts of interest to declare.

Ethical Statement: The author is accountable for all aspects of the work in ensuring that questions related to the accuracy or integrity of any part of the work are appropriately investigated and resolved.

Open Access Statement: This is an Open Access article distributed in accordance with the Creative Commons Attribution-NonCommercial-NoDerivs 4.0 International License (CC BY-NC-ND 4.0), which permits the noncommercial replication and distribution of the article with the strict proviso that no changes or edits are made and the original work is properly cited (including links 
to both the formal publication through the relevant DOI and the license). See: https://creativecommons.org/ licenses/by-nc-nd/4.0/.

\section{References}

1. Available online: https://www.who.int/teams/ncds/ surveillance/monitoring-capacity/gmf

2. Bukhman G, Mocumbi AO, Atun R, et al. The Lancet NCDI Poverty Commission: bridging a gap in universal health coverage for the poorest billion. Lancet 2020;396:991-1044.

3. KC MB. Rheumatic Heart Disease in Nepal: Current Scenario. Nepalese Heart Journal 2016;13:1-2.

4. Mendis S, Puska P, Norrving B. editors. Global atlas on cardiovascular disease prevention and control. Geneva: the World Health Organization in collaboration with the World Heart Federation and the World Stroke Organization, 2011.

5. Shrestha UK, Bhattarai TN, Pandey MR. Prevalence of rheumatic fever and rheumatic heart disease in school children in a rural community of the hill region of Nepal.

doi: 10.21037/asj-21-48

Cite this article as: Koirala B. Generating political support for cardiac surgical care in resource-limited contexts: experience from Nepal. AME Surg J 2022;2:24.
Indian Heart J 1991;43:39-41.

6. Regmi PR, Pandey MR. Prevalence of rheumatic fever and rheumatic heart disease in school children of Kathmandu city. Indian Heart J 1997;49:518-20.

7. Bahadur KC, Sharma D, Shrestha MP, et al. Prevalence of rheumatic and congenital heart disease in schoolchildren of Kathmandu valley in Nepal. Indian Heart J 2003;5 5:615-8.

8. Prajapati D, Sharma D, Regmi PR, et al. Epidemiological survey of Rheumatic fever, Rheumatic heart disease and Congenital heart disease among school children in Kathmandu valley of Nepal. Nepalese Heart Journal 2014;10:1-5.

9. Shrestha NR, Karki P, Mahto R, et al. Prevalence of Subclinical Rheumatic Heart Disease in Eastern Nepal: A School-Based Cross-sectional Study. JAMA Cardiol 2016;1:89-96.

10. Available online: https://catalog.ihsn.org/index.php/ catalog/2138

11. Hosain N, Amin F, Rehman S, et al. Know thy neighbors: The status of cardiac surgery in the South Asian countries around India. Indian Heart J 2017;69:790-6.

12. Available online: https://www.sgnhc.org.np/publication 